Rev. Hist., N²7, vol. 1, Enero-Junio 2020: 7-24

ISSN 0717-8832

https://doi.org/10.29393/RH27-2CHG10002

\title{
Clave hermenéutica del desarrollismo
}

\author{
Hermeneutic key to developmentalism
}

Horacio García Bossio*

\section{RESUMEN}

El "desarrollismo" surgió como un proyecto de política económica dentro de un sector de intelectuales y políticos que alcanzó amplia difusión (especialmente en los llamados "países periféricos") durante las décadas de 1950 y 1960. El notable auge económico de posguerra y la división bipolar del mundo de la Guerra Fría, introdujo la posibilidad de la transformación de las estructuras económicas de los países "en vías de desarrollo" (eufemismo sesentista para clasificar a algunas de las naciones del Tercer Mundo) mediante el crecimiento económico sostenido (medido en términos del PBI) a partir de la industrialización de las otrora economías primarias-exportadoras. Pero crecimiento y desarrollo no tenían el mismo significado para todos los que lo empleaban. Los llamados "desarrollistas" afirmaban que el desarrollo implicaba que la industria pesada les aseguraría a estas naciones un lugar entre los países más poderosos del planeta. El desarrollismo fue entonces una síntesis superadora que presupuso el paso del nacional desarrollo -es decir concebir el crecimiento industrial, aun de la industria pesada, confiando exclusivamente en el financiamiento estatal o con capitales nacionales- al desarrollismo propiamente dicho, que implicaba aceptar como insuficiente el financiamiento y el know how nacional sumando también la cooperación organizacional, científica y tecnológica extranjeras. En esta presentación se propone presentar algunas claves hermenéuticas para comprender el desafío desarrollista en América Latina.

\section{Palabras claves}

Clave hermenéutica- desarrollismo- Amércia Latina- nacional desarrollo

\section{ABSTRACT}

"Developmentalism" emerged as an economic policy project within a sector of intellectuals and politicians that reached wide dissemination (especially in the so-called "peripheral countries") during the 1950s and 1960s. The remarkable post-war economic boom and the bipolar division of the Cold War world introduced the possibility of transformation of the economic structures of the "developing" countries (sixty euphemism to classify some of the Third World nations) through sustained economic growth (measured in terms of GDP) from the industrialization of the former primary economiesexporters But growth and development did not have the same meaning for all who employed it. The socalled "developmentalists" claimed that development implied that heavy industry would assure these nations a place among the most powerful countries on the planet. Developmentalism was then an overcoming synthesis that presupposed the passage of national development -that is, conceiving of industrial growth, even of heavy industry, relying exclusively on state financing or with national capitals-

\footnotetext{
* Doctor en Ciencias Políticas (UCA), Licenciado en Historia (UNLP), director del Departamento de Historia, Facultad de Ciencias Sociales, Pontificia Universidad Católica Argentina. horacio_garciabossio@uca.edu.ar.
} 
to developmentalism proper, which meant accepting as insufficient the financing and national know-how also adding foreign organizational, scientific and technological cooperation. In this presentation it is proposed to present some hermeneutical keys to understand the developmental challenge in Latin America.

\section{Keywords}

Hermeneutic key- developmentalism- Latin America- national development

Recibido: julio 2019

Aceptado: octubre 2019

\section{Introducción: primera aproximación}

"Por primera vez los hombres viven una misma y única historia...finalmente simbolizando en cierto modo la unidad de la especie humana, se utilizan las mismas palabras - capitalismo, socialismo, imperialismo- aunque con significaciones diferentes y a veces contradictorias. Entre las palabras universalmente fundidas quizás sea la de desarrollo la que ocupa el primer lugar..."

Así lo enunciaba en 1962 Raymond Aron en su escrito La teoría del desarrollo y los problemas ideológicos de nuestro tiempo. ${ }^{1}$ Ese halo universal en torno a la problemática del desarrollo, Aron lo identificaba como una prioridad absoluta entre las más diversas naciones y colectividades, sin importar su ubicación geográfica o su sesgo ideológico en el escenario de la bipolaridad de posguerra.

Ahora bien, de este artículo de Arón se puede rescatar que no solo el tema del desarrollo y de su contracara (el subdesarrollo) era una prioridad de las políticas públicas entre los denominados países periféricos, sino que el mismo concepto de desarrollo constituía, además, un desafío hermenéutico. El politólogo francés lo identificaba como tal al afirmar:

"Si bien la palabra desarrollo se utiliza en inglés, alemán, español, portugués y sin duda alguna en todos los demás idiomas, esto no quiere decir que en todas partes se le dé la misma acepción, ni sobre todo, designe la misma tarea en Estados Unidos y en el Brasil, en Guinea y en Francia...quizás la teoría del desarrollo pueda ayudarnos a concretar en qué sentido se halla unificada la humanidad por su técnica y por sus problemas, y dividida y unificada a la vez por sus ideologías."2

Por último, Aron distinguía una triple gestación según la teoría del desarrollo, cada una de las cuales respondía a una cierta hermenéutica conceptual y pragmática. Esas tres vías

\footnotetext{
1 Aron, Raymond. 1962. "La teoría del desarrollo y los problemas ideológicos de nuestro tiempo", en Memorias, Alianza Editorial, Primera edición en español, 1985, p.8.

2 lbíd., p. 8.
} 
respondían entonces a: 1) el estudio estadístico a largo plazo del crecimiento económico; 2) los contrastes entre los países desarrollados y los subdesarrollados (o en vías de desarrollo) y 3 ) la comparación entre las economías y sociedades occidentales y las soviéticas, para identificar las vías capitalistas y las vías centralmente planificadas

Cuando el economista brasilero Pedro Cezar Dutra Fonseca ${ }^{3}$ se pregunta medio siglo después qué es el desarrollismo, invita, como Aron, a comprender en clave de complejidad un concepto esencial del debate intelectual del mundo de posguerra. Coincide en señalar que el concepto de desarrollo (development, développement, desenvolvimento, sviluppo, Entwicklung) fue concebido como una categoría conceptual clara y distinta de sus antecedentes dentro del marco de la economía política: la riqueza (wealth) y el crecimiento económico (growth). Fue entendido como un salto cualitativo de una economía "atrasada" a una economía "moderna" y donde a las variables cuantitativas que reflejaban ese proceso de crecimiento (los indicadores de PBI y renta per capita) se debían anexar otros indicadores cualitativos, que resumieran aspectos socio-culturales: tasas de natalidad y mortalidad, niveles educativos, sanidad y vivienda.

Por ello, Dutra Fonseca distingue dos aproximaciones hermenéuticas que sin embargo no pueden disociarse una de la otra cuando se habla de desarrollismo. Por un lado, se alude a una política económica (a una praxis) y por otro lado (y al mismo tiempo) se refiere a un concepto, a una idea o teoría que corresponde al mundo del pensamiento. A su vez, ambas miradas pueden expresarse como discurso político - una ideología particular que tiene detractores y defensores- o como una escuela o corriente de pensamiento, pretendiendo constituir un corpus epistémico que se incorpore a la teoría económica (la teoría del desarrollo) con status científico. En este sentido, Dutra Fonseca se apoya en la tesis fundacional de Kathryn Sikkink, quien afirma:

“... tanto la teoría como la práctica de los desarrollistas latinoamericanos precedió a la obra más destacada de los teóricos de la modernización (...) gran parte de los trabajos importantes sobre la economía del desarrollo fueron publicados durante o después de las experiencias de los gobiernos desarrollistas en Brasil y la Argentina". ${ }^{4}$

El desarrollismo fue, por ello, praxis y teoría. Como teoría, sin embargo, fue criticada como inconsistente por las universidades del mundo desarrollado (que se consideraban a sí mismas como verdaderas usinas o think tank, ancladas en sus escuelas de pensamiento académico) y

\footnotetext{
${ }^{3}$ Dutra, Pedro. 2015 Desenvolvimentismo. A construçao do concieito, IPEA, Brasilia.

${ }^{4}$ Sikkink, Kathryn.2009, El proyecto desarrollista en la Argentina y Brasil: Frondizi y Kubitschek, Buenos Aires, Editorial Siglo XXI, 1ㅇe edición en castellano, pp. 16-17
} 
fue parte de un clima de ideas, de circulación -asimilación - adaptación en redes intelectuales surgidas desde esos mismos centros que desacreditaban su matriz inicial.

No se puede desconocer en una etapa genética el escrito fundacional del economista argentino Raúl Prebisch, responsable de la Comisión Económica para América Latina (CEPAL), titulado El desarrollo económico de América Latina y sus principales problemas (Santiago de Chile, 1949) -al cual Albert Hirschman Ilamó el Manifiesto- que dio origen al estructuralismo latinoamericano, pues luego de la publicación del nombrado documento ninguna teoría podía seguir sosteniendo, para los países del sub-continente, que era aceptable la vieja doctrina clásica ricardiana de las ventajas comparativas. ${ }^{5}$ Esta primera aproximación al desarrollo espacialmente diferenciado, en torno a un centro industrial y hegemónico que entabla transacciones desiguales con una periferia agrícola y subordinada, sintetizado en el binomio antagónico "centro- periferia", nació del modelo explicativo de Raúl Prebisch, quien a su vez habría tejido redes de intercambio intelectual con la obra del alemán Werner Sombart y del rumano Mihail Manoilescu. Aparte de ellos, también habría influido el chileno-alemán Ernst Wagemann, quien acuñó los términos "ciclo céntrico" y "ciclo periférico" para describir los movimientos de capital en marcos nacionales e internacionales. ${ }^{6}$

Estos autores coincidieron en subrayar la superioridad económica (cabe agregar, tecnológica y cultural) de la industria respecto de la agricultura. Los países especializados en la primera exhibirán en el largo plazo un dinamismo mayor, que se traducirá, inexorablemente, en un ponderable poder en las relaciones internacionales. Las naciones atascadas en las actividades primarias (agricultura, ganadería, minería) eran desfavorecidas debido a la ausencia de una cultura económica adversa al riesgo, a la competencia y a la racionalidad tecnológica. Marcharían, por consiguiente, a remolque de las otras, también en cuestiones de influencia y poder.

Prebisch reconoció que su teoría del deterioro de los términos del intercambio (DTI), clave para sus postulados del estructuralismo y del carácter dependiente de las economías latinoamericanas, lo extrajo leyendo el informe de Hans Singer, Post War price relations between under-development and industrialized countries, publicado luego por la ONU en 1949 con el título de Relative prices of exports and imports of under-developed countries. La síntesis Prebisch- Singer fue el la base conceptual que iluminó el Manifiesto de CEPAL del 1949.7

\footnotetext{
${ }^{5}$ Dosman, Ernesto. 2001 "Los mercados y el Estado en la evolución del manifiesto de Prebisch", en Revista de la CEPAL, N 75, 2001, p. 102.

${ }^{6}$ Love, Joseph .1996. "Las fuentes del estructuralismo latinoamericano", en Desarrollo económico, Volumen 36, № 141 (abril- junio), p. 392.

${ }^{7}$ Garcia Bossio, Horacio.2016., ¿Qué nos hace más Nación? Desfíos del desarrollismo frondicista- frigerista, EDUNLA, 2a edición, p. 61.
} 
La historicidad de las problemáticas económicas, Prebisch la sostenía para defender sus posiciones heterodoxas que criticaban el análisis "ahistórico" de los modelos atemporales de los neoclásicos, provenientes de la mainstream o corriente principal anglosajona, que no consideraban los principios prebischianos como parte de la teoría económica. En palabras del argentino lo explicaba diciendo "... estoy seguro que en Harvard no nos toman en serio, somos economistas de segunda categoría o hasta de tercera; somos economistas subdesarrollados (sic)...". ${ }^{8}$

La verdadera clave hermenéutica del desarrollismo consistiría, pues, en la comprensión por parte de los actores -primero en Brasil Juscelino Kubistchek y su entorno, luego el caso argentino de Arturo Frondizi y sus asesores- del carácter subdesarrollado del continente americano. Convicción que era muy difícil de verbalizar luego de las experiencias "propagandísticamente exitosas" de la etapa anterior nacionalista- populista (ejemplo Vargas y Perón). Para poder ponderar qué implicaba asumir ese "estatuto del subdesarrollo" (Rogelio Frigerio), ese "círculo vicioso de la pobreza" (Ragnar Nurkse) se debe revisar las miradas construidas en la década del cuarenta, cuando se había alimentado el sueño de la autarquía económica, del nacionalismo industrial del modelo sustitutivo mercadointernista, de pleno empleo y de welfare state. Para ellas, el desarrollismo era discursivamente inaceptable, una traición a las convicciones nacionalizantes, ya que se sostenía indefectiblemente en la convicción de tener que recurrir en el corto tiempo al auxilio del capital extranjero (sea a través de IED, inversiones extranjeras directas o de préstamos de los organismos internacionales de crédito) para resolver esa insuficiencia en la tasa de ahorro e inversión nacional, que degeneraba en el status degradante del subdesarrollo estructural. Nacionalismo de fines, pero no de medios, intentó esbozar el asesor de Kubitschek, Helio Jaguaribe, para defender sus propuestas desarrollistas frente a los embates de los grupos nacionalistas quienes, paradójicamente, habrían arrastrado al país a ese peldaño de atraso y subdesarrollo.

Resumiendo. Si los llamados desarrollistas tomaban como punto de partida en su análisis inicial que sus países eran subdesarrollados (tesis), necesariamente, indefectiblemente, "fatalmente" debían recurrir al auxilio externo. Sus opositores nacionalistas (antítesis) se quejaban de esa posición, sin mencionar la ironía de que sus políticas de expansión del gasto público inflacionario y su incapacidad de realizar el take off de la industria liviana del consumo a la industria pesada, habían arrastrado a esos déficits crónicos. El desarrollismo era entonces esa síntesis superadora: era el paso del nacional desarrollo al desarrollismo propiamente dicho. $^{9}$

\footnotetext{
8 Pollock, David .2001. "Entrevista inédita a Prebisch: logros y deficiencias de la CEPAL", en Revista de la CEPAL, N 75, Diciembre, p. 17.

${ }^{9}$ García Bossio,2016. ¿Qué nos hace más nación?, pp.), op. cit., conclusiones finales, pp. 391 y siguientes.
} 
Para quienes encarnaron el desafío del desarrollo, experimentaron el vértigo de estar abriendo nuevos horizontes a un futuro indescriptible que generaba adrenalina y convicciones casi místicas (Brasilia). Esa sensación cerraba la mirada a los obstáculos y a las críticas cotidianas, con la convicción de los profetas que creían ver "un cielo nuevo y una tierra nueva". Así lo expresaba Kubitschek en el epígrafe colocado al inicio de su obra Por que construí Brasília, cuando citaba a San Juan Bosco “...y aparecerá aquí una Gran Civilización, la Tierra Prometida, donde correrá leche y miel. Esas cosas ocurrirán en la tercera generación..." ${ }^{10}$. En ese mismo sentido, la elección de un católico en la Casa Blanca, John Fitzgerald Kennedy y su programa de cooperación, la Alianza para el Progreso (ALPRO) fue recibida con entusiasmo y simpatía y entendida como una señal de que era posible la buena vecindad, que elevaría al continente americano a un horizonte nuevo de posibilidades.

\section{Segunda aproximación: dos posibles hermenéuticas del desarrollismo}

En este apartado se presentarán dos matrices analíticas del fenómeno desarrollista. La primera, desde el análisis de un contemporáneo al gobierno brasilero de Kubistchek. El sociólogo Helio Jaguaribe combina praxis y reflexión, en su doble carácter de asesor del presidente y de intelectual que construye una teoría nueva "anclada en los datos" de la realidad que se quiere transformar (grounded theory). La segunda reflexión se sostiene en la interpretación académica ex post que realizara Sikkink en su tesis doctoral sobre el fenómeno desarrollista. En ambas aproximaciones hermenéuticas se recogen variables comunes como el nacionalismo, la presencia del capital extranjero, el rol planificador del Estado desarrollista y la confianza en mayor o menor medida en el mercado. Estas interpretaciones proponen relativizar algunas categorías estáticas como izquierda- derecha o liberalismo-socialismo.

\section{a) La lógica desenvolvimentista de Jaguaribe}

Para el abogado y sociólogo Helio Jaguaribe (formado en la Pontificia Universidad Católica de Río de Janeiro), ${ }^{11}$ no fue sencilla su transformación discursiva desde sus convicciones iniciales nacional desarrollistas a la prédica de una estrategia decididamente desarrollista, que en la gestión del presidente Kubitschek se plasmó en el denominado "Plan de Metas". Su participación fundacional en 1953 en el grupo de intelectuales cariocas reunidos en el Instituto Brasileiro de Economia e Sociologia e Política (Ibesp), se caracterizó por concebirlo como un espacio de estudio que analizaba los problemas económicos y sociales del Brasil de posguerra.

\footnotetext{
10 Kubitschek, Juscelino. 2000. Por que construí Brasília, publicación del Conselho Editorial del Senado Federal, Colección Brasil 500 Años, Brasilia.

${ }^{11}$ García Bossio, Horacio.2008. "Génesis del Estado desarrollista latinoamericano: el pensamiento y la praxis política de Helio Jaguaribe (Brasil) y de Rogelio Frigerio (Argentina), en Documentos de Trabajo, Facultad de Ciencias Económicas, Universidad Católica Argentina, № 23, abril, p.10.
} 
Asimismo ese Instituto publicó entre 1953 y 1956 los Cadernos de Nosso Tempo, donde asumía plenamente el modelo de desarrollo con capitales nacionales. Luego fue rebautizado en 1955 como Instituto Superior de Estudos Brasileiros (Iseb) y allí se produjo la ruptura con las posiciones "intolerables" de Jaguaribe, quien criticó que el celo nacionalista del Iseb condicionaba la posibilidad de las IED y por lo tanto trababa las posibilidades del verdadero desarrollo del país. Esa controversia quedó plasmada en la obra El nacionalismo en la actualidad brasileña (1958) y años más tarde en El desarrollo económico y el desarrollo político (1962).

Las novedosas categorías analíticas de Jaguaribe en El desarrollo económico y el desarrollo político resultan claves para desandar los intersticios del fraseo de la época sobre el desarrollismo, donde se entablaba un debate teórico-ideológico entre dos posturas, el denominado cosmopolitismo y el nacionalismo. La diferenciación giraba en función de dos cuestiones centrales: 1) la mayor o menor presencia del capital extranjero (IED) frente al capital nacional (y su relación con el capital público) y el mayor o menor grado de libertad en el proceso de crecimiento económico para maximizar el beneficio y asegurar una mayor eficiencia; 2) la planificación estatal de la economía, para direccionar y acelerar el ritmo del desarrollo económico (Jaguaribe no lo dice expresamente así, pero se refiere a la dicotomía entre growth o development). ${ }^{12}$ Es pertinente reforzar las dos categorías sustantivas delimitadas por Jaguaribe. Por un lado, el denominado cosmopolitismo, con sus dos variantes: la liberal y la desarrollista. Por otro, el llamado nacionalismo, con sus dos variantes: la socializante y la desarrollista.

12Jaguaribe, Helio.1964. El desarrollo económico y el desarrollo político, Buenos Aires, EUDEBA, pp. 199 y siguientes. 
Cuadro 1: La lógica desenvolvimentista de Jaguaribe

\begin{tabular}{|c|c|c|}
\hline Posiciones & Cosmopolitismo: & Nacionalismo: \\
\hline & $\begin{array}{l}\text { Presupone IED y la libre } \\
\text { empresa como claves para } \\
\text { el take off de una } \\
\text { economía }\end{array}$ & $\begin{array}{c}\text { Presupone que los sectores productivos nacionales } \\
\text { (con el solo esfuerzo por aumentar la } \\
\text { productividad) pueden sostener el crecimiento } \\
\text { económico }\end{array}$ \\
\hline Variante 1 & $\begin{array}{c}\text { Liberal } \\
\text { Asume las tesis ortodoxas } \\
\text { de la "teoría del derrame" } \\
\text { y de la "teoría del } \\
\text { equilibrio general". }\end{array}$ & $\begin{array}{c}\text { Socializante } \\
\text { Se subdivide en: } \\
\text { a.1. Socializante estatista: asume una matriz de } \\
\text { interpretación marxista. } \\
\text { a.2. Socializante burocrática: } \\
\text { propone la construcción de un "capitalismo social" } \\
\text { en el que coexistiría la empresa pública y privada } \\
\text { para capitalizar la economía y lograr una mayor } \\
\text { distribución del ingreso }\end{array}$ \\
\hline Variante 2 & $\begin{array}{c}\text { Desarrollista } \\
\text { Asume el llamado a las IED } \\
\text { y la formación de una } \\
\text { intelligentsia desarrollista }\end{array}$ & $\begin{array}{c}\text { Desarrollista } \\
\text { Asocia desarrollo económico con la construcción } \\
\text { de la nacionalidad; no se opondría al capital } \\
\text { extranjero como tal, sino tan solo a la tendencia de } \\
\text { que se le entregue la función más dinámica del } \\
\text { desarrollo. }\end{array}$ \\
\hline
\end{tabular}

Fuente: Cuadro de elaboración propia a partir de la obra de: Helio Jaguaribe. 1964. El desarrollo económico y el desarrollo político, op. cit., pp. 199 y siguientes.

\section{a.1) Posición ideológica 1: el cosmopolitismo}

Según Jaguaribe, la tesis central del cosmopolitismo -común para ambas variantes-consistiría en que el desarrollo de un país exige la participación lo más amplia posible del capital extranjero (IED y préstamos), al cual se le atribuía ciertas características que engendrarían, per se, un "círculo virtuoso" (en contraposición al "círculo vicioso del subdesarrollo" descrito por el economista del desarrollo Ragnar Nurkse) bajo la forma de una iniciativa permanente al crecimiento y al aumento de la productividad de una economía. El incentivo a la maximización de la utilidad y a la gestión privada de las empresas son sus pilares. Las variaciones dentro de este enfoque general se inscribirían en: a) el cosmopolitismo liberal, el cual se asimilaría a los sectores sociales que sostenían la convicción de que los principios liberales ortodoxos, en especial la firme aceptación de que la búsqueda del beneficio individual, redundaría en beneficio del interés general; b) el cosmopolitismo desarrollista, en cambio, no se reduce solo a quienes adhirieran a una determinada posición social, sino a una formulación teórica de cierta intelligentsia o think tank desarrollista, que -en su afán por restringir a la mínima expresión la 
intervención del Estado en la economía- insistían en que solo el capital extranjero (frente a la escasa capitalización del país en su particular etapa de subdesarrollo) podría aportar los recursos necesarios para alcanzar el crecimiento económico con el menor costo social posible, sin quedar presos de la ineficiencia, que sería propia tanto del estatismo económico como de la programación nacionalista del desarrollo.

Para nuestra tesis es imprescindible reconocer este concepto, ya que constituye el núcleo central de nuestra argumentación, pues en un determinado momento se produjo una torsión del modelo, que pasó de una estrategia y de un discurso nacional desarrollista originario a otro asociable al cosmopolitismo desarrollista (en lenguaje de Jaguaribe) o al desarrollismo propiamente dicho, según nuestra propia caracterización. ${ }^{13}$

Ahora bien, siguiendo el argumento de Jaguaribe, el cosmopolitismo desarrollista fue muy combatido por:

“... los resultados desnacionalizantes que acarrearía la entrega a grupos extranjeros en control o el predominio sobre ciertos sectores estratégicos de la economía nacional. En los debates suscitados por tales críticas -que asumieron un aspecto bastante sectario- el cosmopolitismo desarrollado fue llevado a hacer causa común con el liberalismo, con el eventual sacrificio de su mensaje desarrollista...". ${ }^{14}$

\section{a.2) Posición ideológica 2: el nacionalismo}

En el campo del nacionalismo Jaguaribe sostenía que -tanto en su vertiente socializante (esta a su vez subdividida en estatista y burocrática) como en la versión desarrollista- por escaso que fuera el capital nacional, el esfuerzo para encarar el desafío del desarrollo tenía que partir de los sectores nacionales. Estos deberían activar un régimen económico que, aumentando la productividad, estuviese "al servicio del país", ya que el desarrollo solamente era históricamente posible si se lo enmarcaba dentro del "elemento nacional". Las IED, por más que tuvieran un verdadero interés por mejorar las condiciones económicas y se presentaran con proyectos viables, nunca podrían resolver el dilema del desarrollo, al no poder obviamente incluir el carácter nacional.

Según Jaguaribe, para el modelo socializante del nacionalismo, los requisitos nacionalistas del desarrollo importaban menos por sí mismos que por el hecho de constituir la condición necesaria para que pudiera realizarse la estatización o la burocratización de la economía

\footnotetext{
${ }^{13}$ Garcia Bossio,.2016. ¿Qué nos hace más Nación?, Desfíos del desarrollismo frondicista- frigerista, EDUNLA, 2a edición, p. 393.

14 Jaguaribe.1964. El desarrollo económico..., p. 203.
} 
brasilera. ${ }^{15}$ En cuanto a las diferencias internas a estas propuestas, Jaguaribe remarcaba que: la fórmula nacional socializante estatista estaba regida por una concepción y una motivación socialista, de tono predominantemente marxista. La vía nacional socializante burocrática se movía en las fronteras de un "capitalismo social" (sic) en el que coexistiría la empresa pública y privada y donde, al menos en el discurso, se proponía una mayor distribución de la renta y una acelerada tasa de capitalización. La tesis central del nacional desarrollismo sostenía, según Jaguaribe, que la promoción del desarrollo económico y la consolidación de la nacionalidad eran dos aspectos correlacionados del mismo proceso emancipador. Para llevarlo adelante “... se preconiza la movilización de la conciencia nacional, en el sentido del desarrollo y de los esfuerzos que este requiere y la adopción de la programación global como técnica para lograr la máxima y mejor utilización posible de los factores disponibles...". ${ }^{16}$

En principio el nacional desarrollismo no se opondría al capital extranjero como tal, sino tan solo a la tendencia de que se le entregase la función más dinámica del desarrollo o a que se le permitiese (mediante el control de los sectores económicos estratégicos, especialmente los recursos naturales) que estas IED pudieran llegar a oponerse o a dificultar la utilización más racional de los recursos nacionales. La elaboración de sus presupuestos teóricos, sus formulaciones doctrinarias y su divulgación se debió a una intelligentsia comprometida, que se encarnó en grupos de investigación y en publicaciones académicas (en Brasil se lo identificaba con el IBESP y el ISEB). De allí que la adhesión a esa "ideología del desarrollo" estuviera subordinada (durante la administración de Juscelino Kubitschek) a la idea del despegue industrial y a una mayor aspiración por la distribución de la renta.

\section{b) Las categorías analíticas de Kathryn Sikkink}

En su tesis doctoral Kathryn Sikkink ${ }^{17}$ anexó a las categorías de cosmopolitas y nacionalistas de Jaguaribe las de acumuladores y reformistas, sugeridas por Albert Hirschman (en un artículo suyo incluido en la obra El nuevo autoritarismo en América Latina). ${ }^{18}$ Hirschman sostenía que en el proceso de crecimiento se presentaban dos funciones básicas: la acumulación y la distribución del capital. Mientras que asociaba a los acumuladores con la función empresarial, los reformistas se identificaban con la tarea distributiva. Sikkink sostiene que el desafío desarrollista puso el acento (en los países con atrasos estructurales) en la función de acumulación, ya que para la autora la definición del desarrollismo era, por antonomasia.

\footnotetext{
15 lbíd., p 204.

16 lbíd., p.206.

17 Sikkink, 2009. El proyecto desarrollista en la Argentina y Brasil, pp. 49 a 51.

${ }^{18}$ Collier, David (compilador).1985., El nuevo autoritarismo en América Latina, Buenos Aires, FCE.
} 
“... un modelo económico basado en ciertas teorías, que defendía determinados valores y proponía un determinado conjunto de políticas públicas (...) Concretamente, en el modelo desarrollista ocupaba un lugar central la industrialización vertical, o sea, la creación de una industria básica o pesada, así como de la infraestructura que facilitaría el surgimiento de una estructura industrial integrada...". ${ }^{19}$

Siguiendo con este razonamiento, Sikkink asocia a los cosmopolitas de Jaguaribe con los acumuladores de Hirschman (pues éstos pondrían mayor énfasis en la necesidad de una urgente capitalización) mientras que nacionalistas y reformistas quedarían relacionados entre sí por la autora, ya que éstos pretendían una relación más equitativa entre la acumulación y las reformas en pos de una mayor distribución. ${ }^{20}$

\section{b.1) Tipologías de Sikkink}

\section{b.1.1) Tipología 1}

En su intento por lograr una caracterización de los sectores políticos e ideológicos que consolidaron el proyecto desarrollista, Sikkink se apoya en las clasificaciones que utilizó Helio Jaguaribe para el Brasil y Albert Hischman para América Latina. En su síntesis, Sikkink reduce el análisis desagregado que describimos de Jaguaribe y lo intercala con las propuestas de Hirschman. Asimismo le anexó las categorías de populismo nacional y desarrollismo, con lo que el resultado final de ese ejercicio intelectual por un lado simplifica el espectro ideológico y, por otro lado, lo confunde restándole su fuerza analítica. Las clasificaciones devienen, entonces, en el siguiente cuadro:

\footnotetext{
${ }^{19}$ Sikkink, 2009. El proyecto desarrollista en la Argentina y Brasil, p 41.

20 Ibíd., p.50.
} 
Cuadro 2: Tipología 1 de Kathryn Sikkink

\begin{tabular}{|c|c|}
\hline Categorías analíticas. Características & Categorías analíticas. Características \\
\hline $\begin{array}{l}\text { a. Cosmopolitas: coincidían en cuanto al núcleo } \\
\text { básico del proyecto desarrollista con los } \\
\text { nacionalistas (industrialización vertical } \\
\text { promovida por la acción del Estado). Se } \\
\text { inclinaban más por la iniciativa privada y la acción } \\
\text { estatal se reducía en alentar a las grandes IED. }\end{array}$ & $\begin{array}{l}\text { a. Nacionalistas: coincidían en cuanto al núcleo } \\
\text { básico del proyecto desarrollista con los } \\
\text { cosmopolitas (industrialización vertical } \\
\text { promovida por la acción del Estado). Exigían } \\
\text { menor inversión externa y mayor intervención } \\
\text { estatal, tanto en la producción como en la } \\
\text { asistencia social. }\end{array}$ \\
\hline $\begin{array}{l}\text { b. Acumuladores: se los identificaba con la } \\
\text { función empresarial, referida al proceso de } \\
\text { acumulación de capital necesario para el } \\
\text { crecimiento. } \\
\text { Sikkink los asocia con los cosmopolitas de } \\
\text { Jaguaribe }\end{array}$ & $\begin{array}{l}\text { b. Reformistas: se los identificaba con la función } \\
\text { distributiva o de reforma, referida a las reformas } \\
\text { sociales necesarias para mejorar el bienestar de } \\
\text { los sectores excluidos y la distribución de la } \\
\text { riqueza en general. } \\
\text { Sikkink los asocia con los nacionalistas de } \\
\text { Jaguaribe }\end{array}$ \\
\hline $\begin{array}{l}\text { c. Finalmente Sikkink también asimila a la } \\
\text { categoría cosmopolitismo desarrollista de } \\
\text { Jaguaribe con algunas posturas que la autora } \\
\text { denominada como alianza desarrollista potencial }\end{array}$ & $\begin{array}{l}\text { c. Finalmente Sikkink también asimila a la } \\
\text { categoría nacional desarrollismo de Jaguaribe con } \\
\text { algunas posturas del llamado populismo nacional }\end{array}$ \\
\hline
\end{tabular}

Fuente: cuadro de elaboración propia a partir de la tesis de Sikkink.2009., pp. 49-52

\section{b.1.2) Tipología 2}

En su tesis, Sikkink sostiene que los líderes políticos de América Latina solo reconocían como válidos algunos modelos de política económica en el mundo de posguerra: el liberalismo, el populismo nacional, el socialismo y el desarrollismo. De estas cuatro opciones, la autora remarca que para la mayor parte de la población -descartando el liberalismo, al que se lo asociaba con las elites consolidadas durante el auge del modelo primario exportador dominante hasta la crisis de 1930- la opción más convincente era alguna forma de industrialización por sustitución de importaciones (ISI), sea populista-nacional o desarrollista. ${ }^{21}$ Sus rasgos principales eran: ${ }^{22}$

\footnotetext{
${ }^{21}$ bíd., pp. 3 y 4.

22 Ibíd., p. 4.
} 
Cuadro 3: Tipología 2 de Kathryn Sikkink

\begin{tabular}{|c|c|}
\hline Populismo-nacional & Desarrollismo \\
\hline $\begin{array}{l}\text { Definición y características } \\
\text { a) Propuso un ISI sencillo, basado en capitales } \\
\text { nacionales más que en inversiones extranjeras. } \\
\text { b) Alentó un proceso de industrialización } \\
\text { horizontal de producción de bienes de consumo. } \\
\text { c) El mercado interno fue visto como motor } \\
\text { prioritario del crecimiento económico. } \\
\text { d) La mayor capacidad de consumo de los } \\
\text { asalariados sostendría una mayor demanda de } \\
\text { bienes, estimulando a las industrias. }\end{array}$ & $\begin{array}{l}\text { Definición y características } \\
\text { a) Industrialización vertical intensiva (ISI } \\
\text { complejo), con rubros prioritarios de incentivo a } \\
\text { la industria pesada (siderurgia, energía, química, } \\
\text { maquinaria, automotriz, bienes de capital). } \\
\text { b) Expansión rápida del proceso de acumulación } \\
\text { de capitales (financiamiento público o con } \\
\text { capitales extranjeros) para ser invertido en la } \\
\text { industrialización. } \\
\text { c) Planificación estatal indicativa para canalizar la } \\
\text { iniciativa privada hacia áreas prioritarias. Si bien } \\
\text { subrayaba principalmente el papel de la incitativa } \\
\text { privada, era imprescindible la orientación de } \\
\text { Estado de la actividad económica, al establecer } \\
\text { las áreas de inversión, ofrecer incentivos a los } \\
\text { inversores, evaluar y financiar los proyectos de } \\
\text { inversión y construir la infraestructura básica } \\
\text { para la industrialización. Si los privados no } \\
\text { deseaban invertir en esos rubros claves, lo } \\
\text { debería hacer solo el Estado o con empresas } \\
\text { mixtas. } \\
\text { d) No se hacía referencia a estos puntos. }\end{array}$ \\
\hline $\begin{array}{l}\text { Rasgos distintivos } \\
\text { Modelo de desarrollo contra-hegemónico y } \\
\text { hegemónico al mismo tiempo: } \\
\text { a) Contra-hegemónico: puso en discusión a la } \\
\text { estrategia primaria exportadora del modelo de } \\
\text { crecimiento hacia fuera (export-led growth } \\
\text { model). } \\
\text { b) Hegemónico: no cuestionó al sistema } \\
\text { capitalista ni propuso independizarse del sistema } \\
\text { capitalista mundial. }\end{array}$ & $\begin{array}{l}\text { Rasgos distintivos } \\
\text { Modelo de desarrollo contra-hegemónico y } \\
\text { hegemónico al mismo tiempo: } \\
\text { a) Contra-hegemónico: puso en discusión a la } \\
\text { estrategia primaria exportadora del modelo de } \\
\text { crecimiento hacia fuera (export-led growth } \\
\text { model). } \\
\text { b) Hegemónico: no cuestionó al sistema } \\
\text { capitalista ni propuso independizarse del sistema } \\
\text { capitalista mundial. } \\
\text { c) Buscaba, más bien, mejorar las condiciones de } \\
\text { inserción en el orden económico internacional. }\end{array}$ \\
\hline
\end{tabular}




\begin{tabular}{|c|c|}
\hline $\begin{array}{l}\text { 3- Diferencias sustanciales } \\
\text { a) Sostiene un sesgo anti-exportador, inherente a } \\
\text { la confianza de lograr con éxito un crecimiento } \\
\text { hacia adentro. } \\
\text { b) ISI "sencillo". } \\
\text { c) Crecimiento impulsado por la demanda. } \\
\text { d) Creía en el crecimiento hacia adentro confiado } \\
\text { en lograr una financiación interna. } \\
\text { e) Promovía a las industrias de capitales } \\
\text { nacionales, orientadas a la promoción de las } \\
\text { pequeñas y medianas empresas. } \\
\text { f) Se acentúa la producción de bienes de } \\
\text { consumo, por lo que se alentaba la } \\
\text { industrialización horizontal. } \\
\text { i) Creían que la economía nacional podría generar } \\
\text { una tasa de ahorro suficiente para capitalizar el } \\
\text { proceso de industrialización nacional. } \\
\text { en la producción. } \\
\text { h) La industria estatal era preferible a los } \\
\text { empréstitos externos y a las IED. }\end{array}$ &  \\
\hline
\end{tabular}

Fuente: elaboración propia a partir de la tesis de Sikkink.2009., pp. 3-4 y 39-42. 


\section{Tercera aproximación: del nacional desarrollo al desarrollismo propiamente dicho}

Si aceptamos como válidas las aproximaciones hermenéuticas de Jaguaribe y de Sikkink, surge una nueva reflexión: el desarrollismo fue entonces una síntesis superadora que presupuso el paso del nacional desarrollo -es decir concebir el crecimiento industrial, aun de la industria pesada, confiando exclusivamente en el financiamiento estatal o con capitales nacionales- al desarrollismo propiamente dicho, que implicaba aceptar como insuficiente el financiamiento y el know how nacional (es decir asumir un estatuto subdesarrollado) aceptando en el corto plazo el financiamiento externo (el big push sugerido por el economista del desarrollo Paul Rosenstein Rodan), sumando también la cooperación organizacional, científica y tecnológica extranjeras. Ahora bien, la otra tensión subyacente fue la que se desplegó en la década de 1960 luego de que sendos golpes de Estado derrocaran a algunos de los así llamados gobiernos desarrollistas. Es decir, si el desarrollo económico presuponía un background democrático desde el punto de vista político-institucional o si podría darse en el contexto de dictaduras militares "modernizantes" (tal como se presentaran, por ejemplos, el golpe de 1964 en Brasil o el Onganiato en Argentina en 1966). Esa discusión traería una nueva dimensión para el análisis que no desplegaremos explícitamente en esta presentación. Solo cabe reconocer el aporte sustantivo del politólogo argentino Guillermo O'Donnell, quien englobó a este tipo de regímenes dentro del concepto de Estado burocrático autoritario. ${ }^{23}$

También podemos sugerir, entonces, una tercera aproximación que tendría como clave hermenéutica desarrollista la mirada institucionalista. Las definiciones sobre el desarrollo en clave político-institucional señalaban que las diferencias entre los países desarrollados y los que estaban "en vías de desarrollo" se debía interpretar por un crecimiento diferencial en sus estructuras políticas y en consecución (o no) de una identidad nacional, de una suerte de cultura del desarrollo. Esos fueron los argumentos tradicionales de Samuel Hungtinton (1968) o de Walt W. Rostow en 1970. En ese mismo contexto, el desarrollismo en clave política se identificó con generar vías de contención para evitar la expansión el comunismo. Esta tercera aproximación la sostiene lúcidamente Natasha Esrow de la Universidad de Essex, en su obra EI desarrollo y el Estado en el siglo XXI ${ }^{24}$. Esrow asume que la política en clave desarrollista de Estados Unidos desde la Alianza para el Progreso hasta ciertas decisiones en los otorgamientos de los créditos el Banco Mundial durante la administración de Mc Namara, asumía esa vertiente político-institucional del desarrollo:

\footnotetext{
${ }^{23}$ O’Donnell, Guillermo .2009., El Estado burocrático autoritario, Buenos Aires, Prometeo Libros.

${ }^{24}$ Esrow, Natasha.2015. El desarrollo y el Estado en el siglo XXI, Ed. MacMillan, Essex, p. 11.
} 
"When Robert McNamara became World Bank president in 1968, the World Bank became more committed to improving the productivity levels of the developing countries. He also recognized that development had a social objective that was aimed at eliminating poverty and global injustices. He paid particular attention to issues such as overpopulation, urbanization, land reform, incomeredistribution, health care and the environment. The Bank started to use social indicators to measure development, which went beyond just looking at economic growth. Overall, there was an emphasis on the quality of growth, which incorporated broader criteria of development". ${ }^{25}$

También Esrow identificaba las tensiones entre las dos grandes vertientes políticoideológicas del desarrollo en los sesenta: la teoría de la modernización con una mirada optimista del desarrollo (la metáfora de la etapas el crecimiento rostownianas) en puja con la teoría de la dependencia y las ideas del estructuralismo cepalino. Esrow los sintetiza en dos citas muy claras. Para la teoría de la modernización de las estructuras institucionales como clave del cambio, sostiene que:

"Modernization theory acknowledges the role of institutions, but only briefl $y$ and tangentially. Modernization theorists acknowledged that institutional reforms, particularly in the political and judicial sectors, can encourage development by protecting property rights and establishing the rule of law. They argued that political structures need to be differentiated to achieve this and that legal sources of authority must be rational". ${ }^{26}$

Mientras que para explicar las bases políticas e institucionales de la dependencia, Esrow asume que era el Estado, como articulador e interventor en el mercado, quien podía terminar con el juego de esas relaciones asimétricas. Resume esa mirada diciendo

"In order to reduce foreign dependence, governments sought to promote the local production of industrialized products by subsidizing the production of strategic substitutes, erecting trade barriers such as tariffs, and manipulating local currencies in order to help manufacturers import capital goods such as heavy machinery more cheaply. ISI was touted as the key means through which developing states could industrialize and catch up with the developed world in light of the disadvantages they confronted. The state would play an important role in ensuring long-term economic growth and capitalist development". ${ }^{27}$

\footnotetext{
25 Ibíd., p. 6.

26 lbíd., p. 30.

27 Ibíd., p. 36.
} 


\section{A modo de conclusión}

A modo de conclusión, proponemos un diseño hermenéutico original que sintetice la complejidad del discurso y de las decisiones políticas del desarrollismo. Sugerimos la imagen de una torsión conceptual (propia de una cinta de Möbius) que explicita gráficamente la transformación-pasaje-mutación-cambiando- sin dejar de ser, de la prédica nacional desarrollista al desarrollismo propiamente dicho. La banda de Möbius resulta sumamente sugerente para el despliegue de la citada torsión conceptual. ¿Por qué? Porque posee propiedades que son proclives de ser asimiladas como analogías o metáforas del proceso de construcción del desarrollismo. Estas son: 1) tiene solo una cara: si se colorea la superficie de una cinta de Möbius, comenzando por la "aparentemente" cara exterior, al final queda coloreada toda la cinta, por tanto, solo tiene una cara y no tiene sentido hablar de cara interior y cara exterior; 2) esta superficie no es orientable: una persona que se desliza "tumbada" sobre una banda de Möbius, mirando hacia la derecha, al dar una vuelta completa aparecerá mirando hacia la izquierda. Si se parte con una pareja de ejes perpendiculares orientados, al desplazarse paralelamente a lo largo de la cinta, se llegará al punto de partida con la orientación invertida. Si se repara en estas propiedades topológicas y se las aplica a la lógica discursiva desarrollista se podrá entender una matriz donde "el adentro y el afuera", "la izquierda y la derecha", "el nosotros y los otros" quedan atrapados en un devenir que permite entender cómo y por qué las alianzas (y rupturas) entre las posturas de los distintos actores políticos son parte del mismo dinamismo contradictorio que se experimentó en la construcción y consolidación del desarrollismo, entendido este en el plano de las ideas y en el de la praxis. Se entenderán también las acusaciones de "entrega, traición y desconcierto", que fueron expuestas tanto por los protagonistas del fenómeno del desarrollo como por los historiadores, politólogos y analistas ex post.

O sea que quienes no ponderaron la experiencia desarrollista en su sentido pleno y de largo plazo (y esto es aplicable, por ejemplo, en el "caso argentino" del tándem Frigerio- Frondizi y en el "caso brasileño" con el binomio Jaguaribe- Kubitschek) quedaron atrapados por su incapacidad de comprensión cabal de un modelo de transformación económica y de salto cualitativo "hacia delante". Paradójicamente, defendiendo los valores del crecimiento nacional se aliaron inconscientemente con aquellos sectores reaccionarios al cambio de la estructura tradicional primaria-exportadora, y colaboraron al fracaso del desarrollismo en América Latina. Esa máxima de Jaguaribe del nacionalismo de fines pero no de medios -que era imprescindible para alcanzar un modelo de industrialización nacional por sustitución compleja de importaciones- no fue aceptada, ni comprendida, ni menos perdonada por los exponentes del modelo mercadointernista de la etapa sustitutiva sencilla, populista y nacionalizante. 
La propuesta de este Dossier es ver si se puede rellenar este itinerario hacia el desarrollismo propiamente dicho en cada caso nacional, analizando su devenir y sus contradicciones, para tratar de comprender sus lógicas discursivas y sus logros, como así también las causas de su fracaso.

\section{Bibliografía}

Aron, Raymond. 1962. "La teoría del desarrollo y los problemas ideológicos de nuestro tiempo", en Memorias, Alianza Editorial, Primera edición en español, 1985.

Collier, David (compilador). 1985. El nuevo autoritarismo en América Latina, Buenos Aires, FCE.

Dosman, Ernesto. 2001. "Los mercados y el Estado en la evolución del manifiesto de Prebisch", en Revista de la CEPAL, N²5, pp.89-105.

Dutra Fonseca, Pedro. 2015. Desenvolvimentismo. A construçao do concieito, IPEA, Brasilia, Julio.

Esrow, Natasha. 2015. El desarrollo y el Estado en el siglo XXI, Ed. MacMillan, Essex.

García Bossio, Horacio. 2008. "Génesis del Estado desarrollista latinoamericano: el pensamiento y la praxis política de Helio Jaguaribe (Brasil) y de Rogelio Frigerio (Argentina)", en Documentos de Trabajo, Facultad de Ciencias Económicas, Universidad Católica Argentina, № 23.

Garcia Bossio, Horacio. 2016. ¿Qué nos hace más Nación? Desfíos del desarrollismo frondicista-frigerista, Buenos Aires, EDUNLA, 2a edición.

Jaguaribe, Helio. 1964. El desarrollo económico y el desarrollo político, Buenos Aires, EUDEBA.

Kubitschek, Juscelino. 2000. Por que construí Brasília, publicación del Conselho Editorial del Senado Federal, Colección Brasil 500 Años, Brasilia.

Love, Joseph. 1996. "Las fuentes del estructuralismo latinoamericano", en Desarrollo económico, Volumen 36, № 141 (abril- junio), pp. 391-402.

O’Donnell, Guillermo. 2009. El Estado burocrático autoritario, Buenos Aires, Prometeo Libros.

Pollock, David. 2001. "Entrevista inédita a Prebisch: logros y deficiencias de la CEPAL", en Revista de la CEPAL, $\mathrm{N}^{\circ} 75, \mathrm{pp} .9-23-$

Sikkink, Kathryn. 2009. El proyecto desarrollista en la Argentina y Brasil: Frondizi y Kubitschek, Buenos Aires, Editorial Siglo XXI, 1ㅇe edición en castellano. 